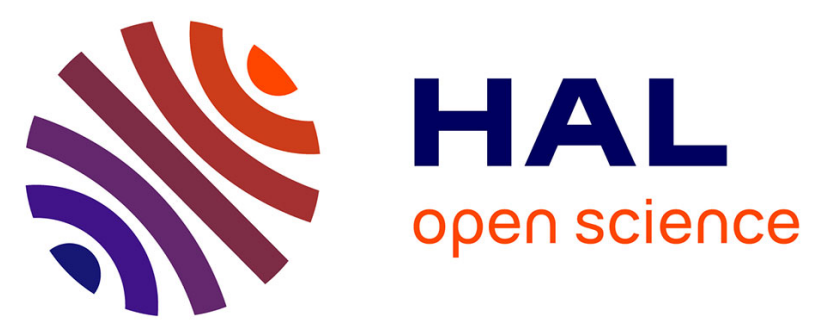

\title{
Vacuum ultraviolet photodynamics of the methyl peroxy radical studied by double imaging photoelectron photoion coincidences
}

\author{
Xiaofeng Tang, Xuejun Gu, Xiaoxiao Lin, Weijun Zhang, Gustavo A. Garcia, \\ Christa Fittschen, Jean-Christophe Loison, Krisztina Voronova, Bálint \\ Sztáray, Laurent Nahon
}

\section{To cite this version:}

Xiaofeng Tang, Xuejun Gu, Xiaoxiao Lin, Weijun Zhang, Gustavo A. Garcia, et al.. Vacuum ultraviolet photodynamics of the methyl peroxy radical studied by double imaging photoelectron photoion coincidences. Journal of Chemical Physics, 2020, The Journal of Chemical Physics, 152 (10), 10.1063/5.0002109 . hal-02960853

\section{HAL Id: hal-02960853 https://hal.univ-lille.fr/hal-02960853}

Submitted on 8 Oct 2020

HAL is a multi-disciplinary open access archive for the deposit and dissemination of scientific research documents, whether they are published or not. The documents may come from teaching and research institutions in France or abroad, or from public or private research centers.
L'archive ouverte pluridisciplinaire HAL, est destinée au dépôt et à la diffusion de documents scientifiques de niveau recherche, publiés ou non, émanant des établissements d'enseignement et de recherche français ou étrangers, des laboratoires publics ou privés. 


\title{
Vacuum ultraviolet photodynamics of the methyl peroxy radical studied by double imaging photoelectron photoion coincidences
}

\author{
Xiaofeng Tang, ${ }^{1, a)}$ Xuejun Gu, ${ }^{1}$ Xiaoxiao Lin, ${ }^{1}$ Weijun Zhang, ${ }^{1,2}$ Gustavo A. Garcia, ${ }^{3, a)}$ \\ Christa Fittschen, ${ }^{4}$ Jean-Christophe Loison, ${ }^{5}$ Krisztina Voronova, ${ }^{6}$ Bálint Sztáray, ${ }^{7}$ \\ Laurent Nahon ${ }^{3}$
}

1 Laboratory of Atmospheric Physico-Chemistry, Anhui Institute of Optics and Fine Mechanics, Chinese Academy of Sciences, Hefei, 230031 Anhui, China

2 School of Environmental Science and Optoelectronic Technology, University of Science and Technology of China, Hefei, 230026 Anhui, China

3 Synchrotron SOLEIL, L’Orme des Merisiers, St. Aubin, BP 48, 91192 Gif sur Yvette, France

4 University Lille, CNRS, UMR 8522, PC2A - Physicochimie des Processus de Combustion et de l’Atmosphère, F-59000 Lilld, France

5 ISM, Université Bordeaux 1, CNRS, 351 cours de la Libération, 33405 Talence Cedex, France

6 Department of Chemistry, University of Nevada, Reno, Reno, Nevada 89557-0216, United States

7 Department of Chemistry, University of the Pacific, Stockton, California 95211, United States

The vacuum ultraviolet (VUV) photoionization of the methyl peroxy radical, $\mathrm{CH}_{3} \mathrm{O}_{2}$, and unimolecular dissociation of internal energy selected $\mathrm{CH}_{3} \mathrm{O}_{2}{ }^{+}$cations were investigated in the 9.7-12.0 eV energy range by synchrotron-based double imaging photoelectron photoion coincidence (i ${ }^{2}$ PEPICO). A microwave discharge flow tube was employed to produce $\mathrm{CH}_{3} \mathrm{O}_{2}$ via the reaction of methyl radicals $\left(\mathrm{CH}_{3}\right)$ with oxygen gas. After identifying and separating the different sources of $\mathrm{CH}_{3}{ }^{+}$from photoionization of $\mathrm{CH}_{3}$ or dissociative photoionization of $\mathrm{CH}_{3} \mathrm{O}_{2}$, the high resolution slow photoelectron spectrum (SPES) of $\mathrm{CH}_{3} \mathrm{O}_{2}$ was obtained exhibiting two broad bands superimposed with a complex vibrational structure. The first band of the SPES is attributed to the $\mathrm{X}^{3} \mathrm{~A}^{\prime \prime}$ and $\mathrm{a}^{1} \mathrm{~A}^{\prime}$ overlapped electronic states of $\mathrm{CH}_{3} \mathrm{O}_{2}{ }^{+}$and the second is assigned to the $\mathrm{b}^{1} \mathrm{~A}^{\prime}$ electronic state with the help of theoretical calculations. The adiabatic ionization energy (AIE) of $\mathrm{CH}_{3} \mathrm{O}_{2}$ is derived as $10.215 \pm 0.015 \mathrm{eV}$, in good agreement with high-accuracy theoretical data from the literature. The vertical ionization energy of the $\mathrm{b}^{1} \mathrm{~A}^{\prime}$ electronic state is measured to be $11.5 \mathrm{eV}$ and this state fully dissociates into $\mathrm{CH}_{3}{ }^{+}$and $\mathrm{O}_{2}$ fragments. The $0 \mathrm{~K}$ adiabatic appearance energy $\left(\mathrm{AE}_{0 \mathrm{~K}}\right)$ of the $\mathrm{CH}_{3}{ }^{+}$fragment ion is determined to be $11.1548 \pm 0.02 \theta \mathrm{eV}$.

a) Author to whom correspondence should be addressed. Electronic mail: tangxf@aiofm.ac.cn (XT), gustavo.garcia@synchrotron-soleil.fr (GG) 


\section{INTRODUCTION}

Organic peroxy radicals $\left(\mathrm{RO}_{2}\right)$ are key reaction intermediates in the low temperature oxidation of hydrocarbons and play an essential role in combustion and atmospheric chemistry. ${ }^{1,2}$ In the atmosphere they are involved in the tropospheric "self-cleansing" mechanism, controlling the cycling of radicals and the formation of secondary pollutants such as ozone and secondary organic aerosols (SOA). The structure, thermochemistry and kinetics of $\mathrm{RO}_{2}$ are of considerable importance in order to fully understand their chemistry in the atmosphere. In the past decades many advances have been made on the detection and analysis of $\mathrm{RO}_{2}$ by the constant development of analytical methods such as absorption spectroscopy, ${ }^{1,3}$ cavity ring down spectroscopy (CRDS), ${ }^{4}$ chemical ionization mass spectrometry (CIMS) ${ }^{5}$ and photoionization mass spectrometry (PIMS) $)^{6,7}$.

The methyl peroxy radical, $\mathrm{CH}_{3} \mathrm{O}_{2}$, is the simplest and most abundant alkyl peroxy radical in the atmosphere which has attracted a great deal of attention. The structure of $\mathrm{CH}_{3} \mathrm{O}_{2}$ and its thermochemistry have been studied extensively both experimentally and with quantum-chemical methods. The neutral $\mathrm{CH}_{3} \mathrm{O}_{2}$ at the $\mathrm{X}^{2} \mathrm{~A}^{\prime \prime}$ ground state has a $\mathrm{Cs}$ symmetry with electronic configuration of $\left(1 a^{\prime}\right)^{2} \ldots\left(9 a^{\prime}\right)^{2}\left(2 a^{\prime \prime}\right)^{2}\left(10 a^{\prime}\right)^{2}\left(3 a^{\prime \prime}\right)^{1.8}$. Removing an electron from the $10 \mathrm{a}^{\prime}$ orbital in photoionization can lead to two spin cationic states, the $\mathrm{X}^{3} \mathrm{~A}^{\prime \prime}$ ground electronic state and the $\mathrm{a}^{1} \mathrm{~A}^{\prime}$ first excited state. Theoretical calculations with a complete basis set method using the atomic pair natural orbital expansion (CBSAPNO) at the QCISD(T)/CBS level of theory were performed by Meloni et al. and predicted the adiabatic ionization energy (AIE) of $\mathrm{CH}_{3} \mathrm{O}_{2}$ at $10.21 \mathrm{eV} .{ }^{6}$ Voronova et al. also carried out electronic structure calculations at the $\operatorname{CCSD}(\mathrm{T}) /$ aug-cc$\mathrm{pVQZ} / / \mathrm{CCSD} /$ aug-cc-pVTZ level and predicted the same theoretical value of AIE = $10.21 \mathrm{eV} .^{9}$

$\mathrm{CH}_{3} \mathrm{O}_{2}{ }^{+}$cation and its kinetics were studied experimentally by mass spectrometry with electron impact ionization ${ }^{10}$ and vacuum ultraviolet (VUV) lamp photoionization. ${ }^{11}$ Meloni et al. investigated the synchrotron VUV photoionization of small alkyl peroxy radicals using the multiplexed photoionization mass spectrometer (MPIMS) at the Advanced Light Source, and found that most of these cations are unstable, whereas $\mathrm{CH}_{3} \mathrm{O}_{2}{ }^{+}$is among the very few bound alkyl peroxy cations. ${ }^{6,12}$ Using the photoionization 
efficiency curve (PIE) of $\mathrm{CH}_{3} \mathrm{O}_{2}$ they determined the AIE to be $10.33 \pm 0.05 \mathrm{eV}$, and the appearance energy of the $\mathrm{CH}_{3}{ }^{+}$fragment ion from the dissociative photoionization (DPI) of $\mathrm{CH}_{3} \mathrm{O}_{2}$ was reported as $11.16 \pm 0.05 \mathrm{eV}$. The PIE of $\mathrm{CH}_{3} \mathrm{O}_{2}$ was also measured at Hefei synchrotron by using a VUV photoionization time-of-flight (TOF) mass spectrometer and its AIE was reported to be $10.32 \pm 0.03 \mathrm{eV}{ }^{7}$ Bernstein et al. also observed $\mathrm{CH}_{3} \mathrm{O}_{2}{ }^{+}$and obtained the rotationally resolved infrared (IR) spectrum of $\mathrm{CH}_{3} \mathrm{O}_{2}$ by IR+VUV laser photoionization mass spectrometry. ${ }^{13}$

Building on the capabilities of photoionization mass spectrometry (PIMS) and photoelectron spectroscopy (PES), photoelectron photoion coincidence spectroscopy (PEPICO) analyzes both the photoelectrons and photoions in coincidence, and offers richer and more accurate information on energetics. ${ }^{14-16}$ Particularly, mass-selected threshold PES (ms-TPES) can be measured, which provides high-resolution thermochemical information with structure specific insights. ${ }^{9}$ 17, 18 Recently, Voronova et al. performed imaging PEPICO experiments at the Swiss Light Source (SLS) and reported the AIE of $\mathrm{CH}_{3} \mathrm{O}_{2}$ and the adiabatic appearance energy $\left(\mathrm{AE}_{0 \mathrm{~K}}\right)$ of the $\mathrm{CH}_{3}{ }^{+}$ fragment ion as $10.265 \pm 0.025$ and $11.164 \pm 0.010 \mathrm{eV}$, respectively, by fitting the envelope of the TPES and the breakdown diagram. ${ }^{9}$

In this work, we present a detailed VUV photoionization and dissociative photoionization study of $\mathrm{CH}_{3} \mathrm{O}_{2}$ by using the high energy resolution of the VUV beamline DESIRS at synchrotron SOLEIL and the state-of-the-art method of double imaging photoelectron photoion coincidence (i ${ }^{2}$ PEPICO). ${ }^{16},{ }^{19}$ The full slow photoelectron spectrum (SPES) of $\mathrm{CH}_{3} \mathrm{O}_{2}$ is acquired in the 9.7-12.0 eV energy range and assigned with the help of theoretical calculations, which are indispensable as the unfavorable Franck-Condon factors (FCF) combined with the proximity of the first electronically excited state render the measurement of the AIE difficult. The high photon energy resolution combined with the slow photoelectron technique provide a more precise comparison to the existing calculations leading to an increased accuracy of the AIE. In the following sections, we will first describe the experimental setup and methodology to generate $\mathrm{CH}_{3} \mathrm{O}_{2}$ using a microwave discharge flow tube. Then a procedure to separate the cold molecular beam and the thermal background gas 
components within the photoionization region is introduced and used to get positionfiltered and mass-selected SPES.

\section{EXPERIMENTAL SETUP}

The experiments were performed at the VUV beamline DESIRS with the $\mathrm{i}^{2} \mathrm{PEPICO}$ spectrometer DELICIOUS III at synchrotron SOLEIL, France. A flow tube combined with a microwave discharge generator was employed as reactor to produce radicals and initiate their reactions. The configurations of the beamline, the $i^{2}$ PEPICO spectrometer and the flow tube have already been introduced before ${ }^{16-21}$ and only a brief description is given here.

On the DESIRS beamline, synchrotron photons emitted from a variable polarization undulator were dispersed by a $6.65 \mathrm{~m}$ normal incidence monochromator equipped with four gratings to cover the energy range of $5-40 \mathrm{eV} .^{20}$ In our experiments the $200 \mathrm{l} . \mathrm{mm}^{-1}$ grating providing high photon flux was used and the photon energy resolution was set at $\sim 3$ meV. A gas filter filled with Ar was adopted to suppress high-order harmonics and the absolute photon energy was calibrated on-line with an accuracy of \pm 1 meV using the resonant absorption lines of $\mathrm{Ar}^{22}$

The flow tube was composed of a main tube with an inner diameter of $2.5 \mathrm{~cm}$ and a collinear sliding injector, installed inside the source chamber of SAPHIRS, the permanent molecular beam endstation on the beamline. ${ }^{19,21}$ The microwave discharge generator running at $2.45 \mathrm{GHz}$ (Sairem GMP $03 \mathrm{KSM}$ ) was mounted perpendicularly to the gas flow and initiated radical reactions in the flow tube. The pressure inside the flow tube was measured by a gauge (Varian CDG 500) and maintained at 1-10 Torr by a closedloop feedback throttle valve. ${ }^{21}$ After passing through the flow tube, the gas mixture was sampled and expanded through two skimmers (1 mm diameter) into the ionization chamber of SAPHIRS.

The gas mixture crossed the photon beam at the center of the $i^{2} \mathrm{PEPICO}$ spectrometer. ${ }^{16}$ Electrons and ions produced in photoionization were extracted and accelerated in opposite directions towards an electron velocity map imaging (VMI ${ }^{23}$ device and an ion modified Wiley-McLaren TOF 3D-momentum imaging analyzer. A 
position sensitive detector (PSD, DLD 80, Roentdek) was mounted to collect electron images which were filtered with ion mass- and momentum-selection in coincidence. An Abel inversion algorithm, pBasex, was used to analyze electron images to get PES or SPES. ${ }^{24,25}$ A custom-made PSD (40 mm diameter) was used for ion detection whose 3D momentum distribution was determined by TOF and transverse position measurements.

\section{RESULTS AND DISCUSSION}

Two kinds of experiments have been performed to unravel the double origin of $\mathrm{CH}_{3}{ }^{+}$ observed in the experiment: photoionization of the methyl radical, $\mathrm{CH}_{3}$, and dissociative photoionization of $\mathrm{CH}_{3} \mathrm{O}_{2}$. The first experiment was performed without adding oxygen into the flow tube. The methyl radicals were produced through the hydrogen-abstraction reaction (1) of fluorine atoms with methane (30 sccm, Air Liquide), where fluorine atoms were generated in the microwave discharge of a mixture of $5 \% \mathrm{~F}_{2}$ diluted in helium (10 sccm, Air Liquide).

$$
\mathrm{F}+\mathrm{CH}_{4} \rightarrow \mathrm{CH}_{3}+\mathrm{HF}
$$

The second experiment was carried out by adding a large amount of oxygen into the flow tube (600 sccm, Air Liquide) to enhance the production of $\mathrm{CH}_{3} \mathrm{O}_{2}$ via the reaction ${ }^{7}$

$$
\mathrm{CH}_{3}+\mathrm{O}_{2}+\mathrm{M} \rightarrow \mathrm{CH}_{3} \mathrm{O}_{2}+\mathrm{M}
$$

where $\mathrm{M}$ represents molecules removing the internal energy of the nascent $\mathrm{CH}_{3} \mathrm{O}_{2}$ by collisions. For both experiments, helium was added as carrier gas and the overall flow rate was fixed at $1740 \mathrm{sccm}$ with the pressure inside the flow tube at 1.6 Torr.

\section{A. Time-of-Flight Mass Spectra and Ion Images}

The photoionization mass spectrum in the absence of oxygen was measured at $\mathrm{h} v=$ $12.0 \mathrm{eV}$ and is presented in Fig. 1(a). The most intense peak is observed at $\mathrm{m} / \mathrm{z}=15$ and assigned to the methyl radical, produced from reaction (1). Minor peaks are also observed at $m / z=14,26,28$ and 30 in the mass spectrum and are assigned to $\mathrm{CH}_{2}, \mathrm{C}_{2} \mathrm{H}_{2}, \mathrm{C}_{2} \mathrm{H}_{4}$ and $\mathrm{C}_{2} \mathrm{H}_{6}$, respectively, generated from secondary reactions in the flow tube.

After the addition of oxygen, the photoionization mass spectrum at $\mathrm{h} v=12.0 \mathrm{eV}$ was measured and is presented in Fig. 1(b). Besides the above-mentioned peaks, another intense peak at $\mathrm{m} / \mathrm{z}=47$ appeared which is assigned to $\mathrm{CH}_{3} \mathrm{O}_{2}$ produced from reaction 
(2). The more intense peak at $m / z=30$ is attributed to two isobaric products, $\mathrm{C}_{2} \mathrm{H}_{6}$ and $\mathrm{H}_{2} \mathrm{CO}$ by the associated mass-selected SPES (ms-SPES). The peak of $\mathrm{m} / \mathrm{z}=32$ corresponds to $\mathrm{O}_{2}{ }^{+}$from the residual high-order/high-harmonic photoionization of oxygen presented in high concentration in the flow tube.
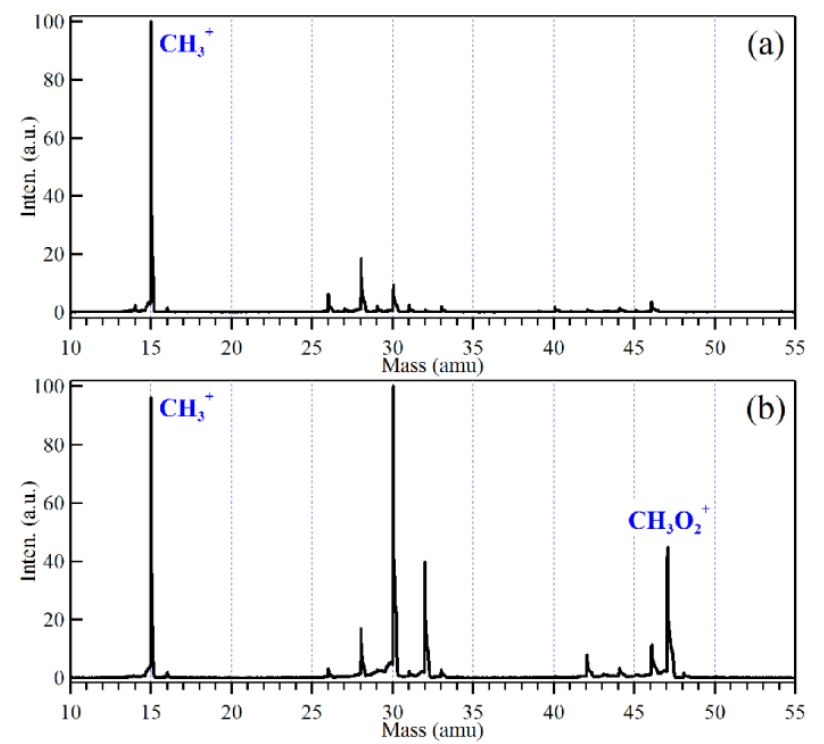

FIG. 1. Synchrotron photoionization time-of-flight mass spectra measured at $h v=12.0$ $\mathrm{eV}$ (a) without oxygen and (b) adding oxygen into the flow tube.

The ion images of $\mathrm{CH}_{3}{ }^{+}$and $\mathrm{CH}_{3} \mathrm{O}_{2}{ }^{+}$were acquired with the time-focusing mode of DELICIOUS $\mathrm{III}^{16}$ and are displayed in Fig. 2, together with their intensity projections along the $y$-axis direction. In this mode, the final position on the detector is a convolution of the initial position and particle velocity. Parent ions, such as the ones shown in Fig. 2, possess narrow velocity distributions, especially for the ions formed in the molecular beam (MB), so that the dispersion seen in the ion positions is mainly related to the size of the interaction region. Parent ions formed in the MB will also have a net velocity along the MB's direction, as seen in Fig. 2, where MB propagates from east to west along the $\mathrm{x}$ axis direction, and the propagation direction of synchrotron radiation (SR) is along the $y$ axis. Therefore, unlike $\mathrm{VMI}{ }^{23}$ the time-focusing mode is utilized to map the photoionization region allowing the separation of ions from MB and the thermal background, plus the selection of on-axis ions to increase the ion mass and ion and electron kinetic energy resolution, which can be viewed as an adjustable virtual skimmer. $^{16,19}$ 
The ion images and their intensity projections can be divided into two parts: the region of interest (ROI) from $\mathrm{MB}$ and the "Back" from the background gas in the photoionization region. In the ROI and as mentioned above, the ions from MB have a defined velocity along the $\mathrm{MB}$ direction and are therefore shifted from the image center. ${ }^{19,21}$ For the Back, the ions from the thermal background gas do not have velocity along the MB direction and appear at the image center. With the coincidence scheme we can get the position-filtered electron and ion signals correlating only to the cold ROI or the thermal ions of a given mass. ${ }^{16,21}$ Note that this scheme also reduces the false coincidences, because for an event to be considered the ion needs to arrive at the expected TOF and at the expected position, similar to the scheme reported by Sztáray et $a^{26}$
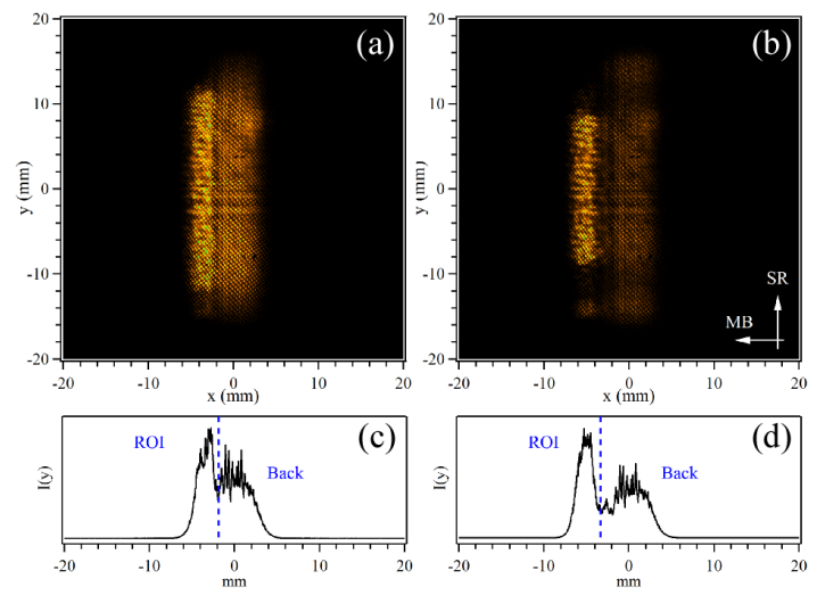

FIG. 2. Mass-selected ion images and their intensity projections along the $y$-axis corresponding to (a, c) $\mathrm{CH}_{3}{ }^{+}$and (b, d) $\mathrm{CH}_{3} \mathrm{O}_{2}{ }^{+}$, recorded at $\mathrm{hv}=12.0 \mathrm{eV}$, where the left ROI correlates to the part of molecular beam with a distance away from the image center, and the right Back part to the background in the photoionization region.

\section{B. $\mathrm{CH}_{3}{ }^{+}$from Photoionization or Dissociative Photoionization}

Mass-selected photoelectron kinetic energy matrices show the photoelectron signal as a function of photon energy and electron kinetic energy for a particular mass (presently only including the ROI part in Fig. 2). ${ }^{18,27}$ From these matrices the SPES is extracted by integrating the photoelectron signal along a constant ionic state (diagonal line), up to a maximum value, $\mathrm{KE}_{\max }$, according to the expression,

$$
S P E S(h v)=\int_{0}^{K E_{\max }} A(h v+K E, K E) d K E
$$


where $A(h v, K E)$ is the photoelectron kinetic energy matrix as plotted in Figure 3.

This allows both an implicitly correct hot electron subtraction, and a more relaxed compromise between resolution and statistics since larger values of $\mathrm{KE}_{\max }$ are typically used with respect to TPES. The photoelectron kinetic energy matrices corresponding to the $m / z=15$ ions without and with the addition of oxygen gas into the flow tube were measured with a photon energy step size of $10 \mathrm{meV}$ and are presented in Fig. 3(a) and (c). In both photoelectron matrices, the electron signal appears at $\sim 9.8 \mathrm{eV}$, and the electron kinetic energy increases linearly with photon energy in accordance with a direct photoionization of the methyl radical. But, after the addition of oxygen gas into the flow tube, further weak signals can be identified with small electron kinetic energy at the lower-right corner of Fig. 3(c), in the 11.2-12.0 eV photon energy range.

The ms-SPES corresponding to the $\mathrm{m} / \mathrm{z}=15$ ions are obtained from the photoelectron matrices and presented in Fig. 3(b) and (d), with 10-times-magnified data in blue. ${ }^{25}$ The ms-SPES records the signal of photoelectrons with near-zero kinetic energy $\left(\mathrm{KE}_{\max }=100 \mathrm{meV}\right)$ and its energy resolution can be comparable to the traditional TPES. ${ }^{18,27-29}$ As shown in Fig. 3, the two ms-SPES mainly exhibits the same structures and their intense peaks are located at $\mathrm{h} v=9.838 \mathrm{eV}$, corresponding to the AIE of the methyl radical. In addition, several minor peaks can be observed close to the main peak which are ascribed to the $\mathrm{v}_{2}$ umbrella vibrational excitations in the photoionization. ${ }^{30,31}$ In Fig. 3(b), the electron signal at the high energy part of the ms-SPES is almost zero, as seen in the 10 times magnified data in blue, due to the minute resonant photoionization possibility of the methyl radical within this energy range ${ }^{30}$. 

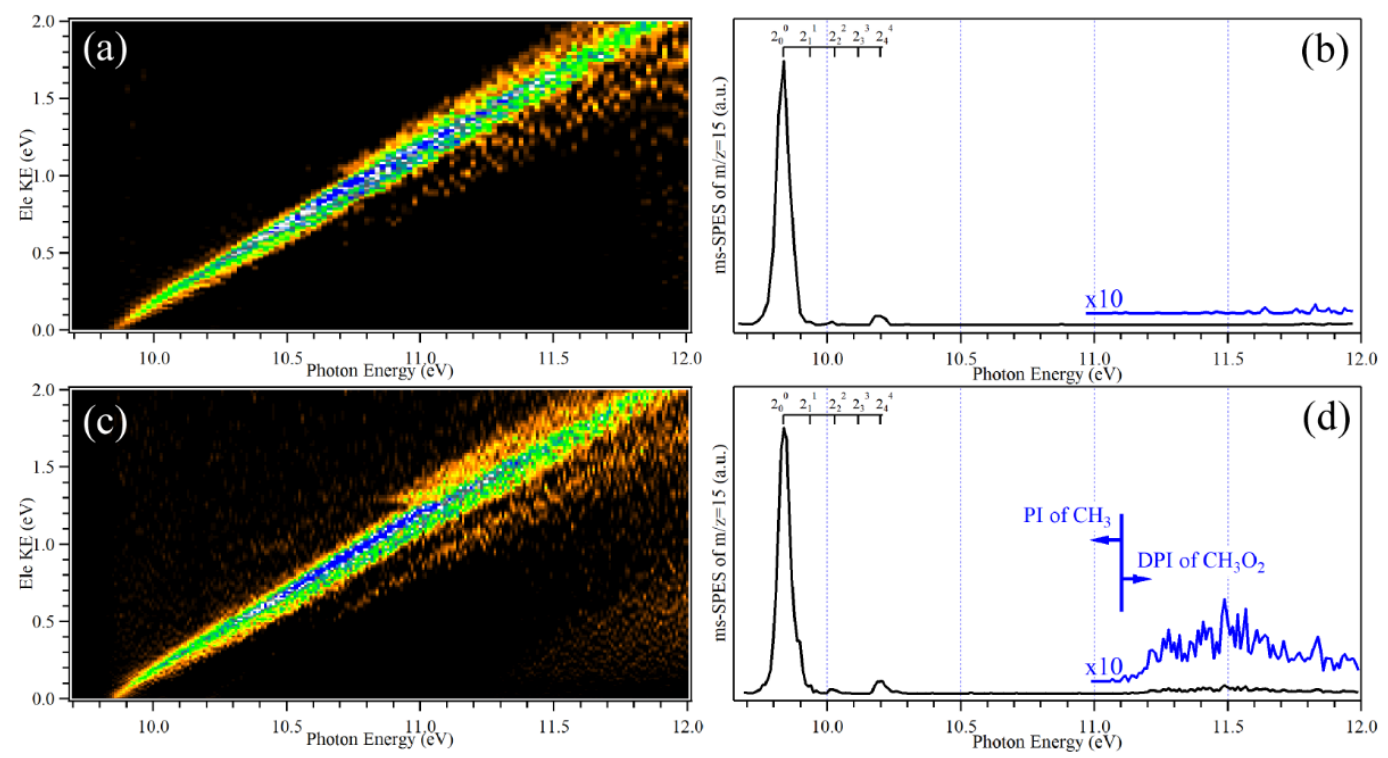

FIG. 3. Mass-selected photoelectron kinetic energy matrices corresponding to $\mathrm{CH}_{3}{ }^{+}$ions acquired (a) without and (c) with adding oxygen gas into the flow tube; (b) and (d) are the corresponding mass-selected slow photoelectron spectra (ms-SPES), with 10 times magnified data in blue.

However, as shown as the blue magnified data in Fig. 3(d), the ms-SPES acquired with adding oxygen gas is different from the one without oxygen in Fig. 3(b), with additional signal appearing with the addition of oxygen. Therefore, electrons corresponding to the mass of $m / z=15$ in Fig. 3(d) have a double origin: below $11.1 \mathrm{eV}$ $\mathrm{CH}_{3}{ }^{+}$and the corresponding electrons are produced by direct photoionization (PI) of the methyl radical, while above $11.1 \mathrm{eV} \mathrm{CH}_{3}{ }^{+}$is created due to DPI of $\mathrm{CH}_{3} \mathrm{O}_{2}{ }^{6}{ }^{6} 9$

\section{SPES of $\mathrm{CH}_{3} \mathrm{O}_{2}$}

The photoelectron kinetic energy matrix and the ms-SPES corresponding to the mass of $\mathrm{m} / \mathrm{z}=47$ are presented in Fig. 4. The electron signal appears at $\sim 10.2 \mathrm{eV}$ and exhibits a broad band in the ms-SPES in the 10.2-11.1 eV energy range. The electron signal is almost zero at $h v>11.1 \mathrm{eV}$, due to the dissociative character of $\mathrm{CH}_{3} \mathrm{O}_{2}^{+}$prepared at high energy, as described above. 

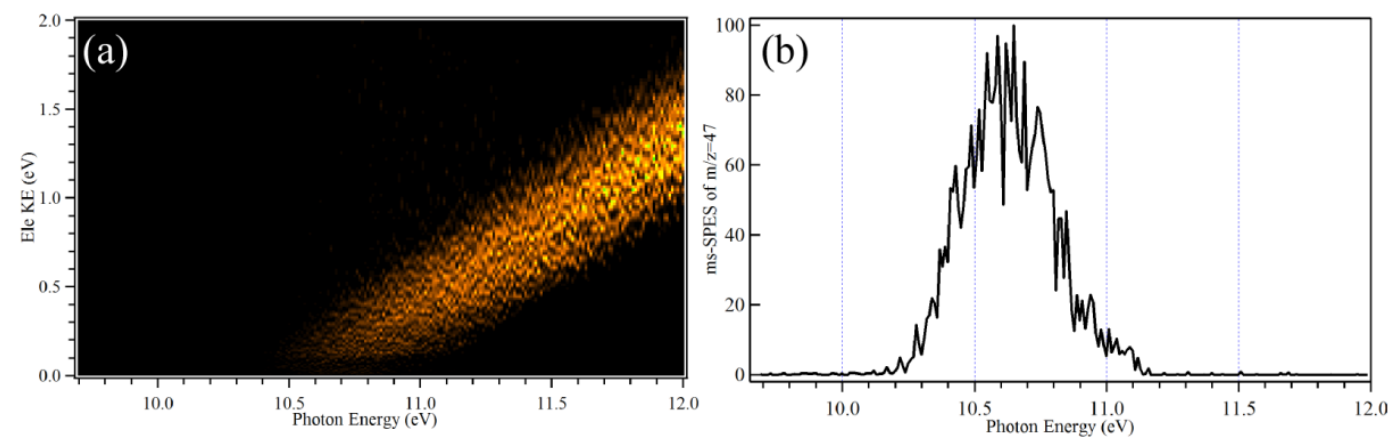

FIG. 4. (a) Photoelectron kinetic energy matrix and (b) mass-selected slow photoelectron spectrum corresponding to the mass of $m / z=47$.

By combining the ms-SPES of $m / z=15$ and 47 (in Fig. 5a), the full SPES of $\mathrm{CH}_{3} \mathrm{O}_{2}$ is retrieved, for the first time, in the 9.7-12.0 eV energy range and presented as a black solid line in Fig. 5(b). Previous high-accuracy calculations showed that the AIEs of the $\mathrm{X}^{3} \mathrm{~A}^{\prime \prime}$ ground electronic state and the $\mathrm{a}^{1} \mathrm{~A}^{\prime}$ first excited state of $\mathrm{CH}_{3} \mathrm{O}_{2}{ }^{+}$are located at 10.21 and $10.43 \mathrm{eV}$, respectively, ${ }^{6,9}$ and contribute to the first band of the SPES in the 10.2-11.1 eV photon energy range. However, due to the small energy difference between these two cationic states and their vibrational congestion, they are overlapped and cannot be separated in the SPES even with higher energy resolution.

Voronova et al. calculated the Franck-Condon factors involved in the photoionization and found that the strongest active vibrational modes are the OOC bend $\left(320 \mathrm{~cm}^{-1}\right)$ and the CO stretch $\left(505 \mathrm{~cm}^{-1}\right)$ for the $\mathrm{X}^{3} \mathrm{~A}^{\prime \prime}$ ground electronic state, and the OOC bend $\left(497 \mathrm{~cm}^{-1}\right)$ and the $\mathrm{OO}$ stretch $\left(1578 \mathrm{~cm}^{-1}\right)$ for the $\mathrm{a}^{1} \mathrm{~A}^{\prime}$ excited state. ${ }^{9}$ Voronova et al. used detailed Franck-Condon simulations to fit the TPES, in which the $\mathrm{CH}_{3}-\mathrm{OO}$ torsional mode was treated as a hindered rotor and obtained an AIE of $\mathrm{CH}_{3} \mathrm{O}_{2}$ at $10.265 \pm 0.025 \mathrm{eV} .{ }^{9}$ However, as their experimental spectrum was of lower resolution and lacked a clear-vibrational structures, the fitting was mainly based on the overall envelope of the TPES. The main uncertainty in the AIE was attributed to the relative ratio of the singlet and triplet transition intensities and they found that Franck-Condon simulations with AIEs between 10.24 and $10.29 \mathrm{eV}$ provided acceptable fits to the data. 

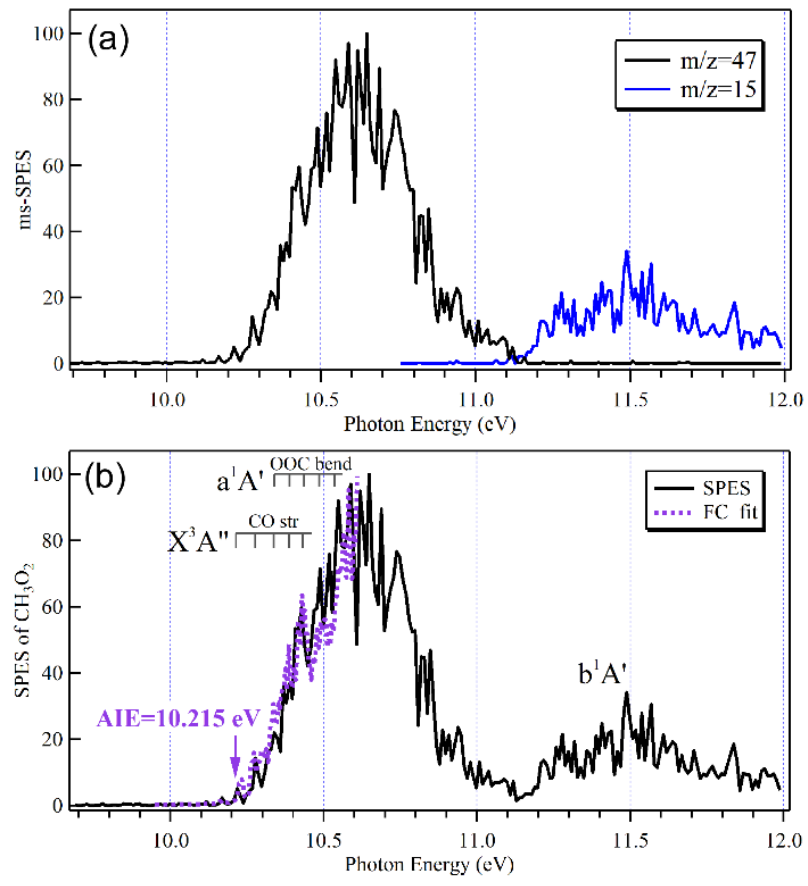

FIG. 5. (a) Mass-selected slow photoelectron spectra (SPES) corresponding to $\mathrm{m} / \mathrm{z}=47$ and 15 ions; (b) SPES of $\mathrm{CH}_{3} \mathrm{O}_{2}$ (black) and its partial Franck-Condon fitting (purple).

In comparison to the literature TPES $^{9}$ (see Fig. S1), owing to the high energy resolution of the DESIRS beamline and of the DELICIOUS III setup, ${ }^{16,19,20}$ the present SPES exhibits a defined vibrational structure, especially at the beginning of the first band. We have also tried to fit the overall SPES with the calculated Franck-Condon factors ${ }^{9}$ and cannot get a satisfying result, due to the two overlapped $\mathrm{X}^{3} \mathrm{~A}^{\prime \prime}$ and $\mathrm{a}^{1} \mathrm{~A}^{\prime}$ states with a complex congested profile. So, we focused on the fitting of the vibrational peaks at the beginning of the SPES and a satisfactory Franck-Condon fitting, taking into account the contributions of both overlapped states, is obtained for the well-resolved and intense vibrational peaks below $10.6 \mathrm{eV}$, as shown in Fig. 5(b). The in region, correspending to the beginning of the first band, are mainly atmibuted to the $6 \theta$ stretching and the $\theta \ominus G$ bending modes of the $X^{2} A^{\prime \prime}$ ground state, and the $\theta \theta 6$ bending of the $a^{1} \mathrm{~A}^{\prime}$ exterimental and simulated spectra is achieved assuming an AIE of $\mathrm{CH}_{3} \mathrm{O}_{2}$ of $10.215 \pm 0.015 \mathrm{eV}$, in excellent agreement with the literature high-accuracy theoretical data of $10.21 \mathrm{eV},{ }_{-}^{6,9}$ and the error bar mainly includes the contributions of the energy uncertainty in the Franck-Condon fitting and the synchrotron photon energy resolution. The vibrational peaks in this 
regionbelow $10.6 \mathrm{eV}$, corresponding to the beginning of the first band, are mainly attributed to the $\mathrm{CO}$ stretching and the OOC bending modes of the $\mathrm{X}^{3} \mathrm{~A}^{\prime \prime}$ ground state, and the OOC bending mode of the $\mathrm{a}^{1} \mathrm{~A}^{\prime}$ excited state, as shown the assignments in Fig. 5(b), whereas the two peaks with very weak intensities at $h v=10.11$ and $10.17 \mathrm{eV}$ in the SPES are ascribed to the hot bands involved in the photoionization.

Fig. S1 shows a comparison between the TPES of Ref. 9 and our SPES. In the region above $\sim 10.7 \mathrm{eV}$ the TPES band is larger which is somewhat attributed to the temperature differences between the two measurements as determined from the breakdown diagrams (vide infra). The internal temperature of the free radical was determined to be $330 \pm 30 \mathrm{~K}$ at the SLS, ${ }^{9}$ whereas it was $160 \pm 40 \mathrm{~K}$ in our experiment (see Section III.D).

The second band of the ms-SPES locatese in the 11.1-12.0 eV energy range and its vertical ionization energy (VIE) lies at $\sim 11.5 \mathrm{eV}$, as seen in Fig. 5. The second band is assigned with the aid of theoretical calculations as the second excited electronic state, $\mathrm{b}^{1} \mathrm{~A}^{\prime}$. Concretely, the geometry optimization and energy calculation of the ground electronic state of the neutral $\mathrm{CH}_{3} \mathrm{O}_{2}$ radical are performed at the DFT B3LYP/6-311G* level of theory, whereas those of the excited electronic states of the $\mathrm{CH}_{3} \mathrm{O}_{2}{ }^{+}$cation are at the TDDFT B3LYP/6-311G* level of theory. All these calculations are carried out by using the Gaussian 09 program package. The theoretical calculations show that the electronic configuration of the $b^{1} A^{\prime}$ cationic state is $\left(1 a^{\prime}\right)^{2} \ldots\left(9 a^{\prime}\right)^{2}\left(2 a^{\prime \prime}\right)^{2}\left(10 a^{\prime}\right)^{2}$ and its VIE is theoretically calculated to belocates at $11.56 \mathrm{eV}$-at the TDDFT B3LYP/6-311G* level, ${ }^{32}$ agreeing well with the experimental value of $11.5 \mathrm{eV}$. We also calculated the AIE (VIE) of the third excited electronic state $\mathrm{A}^{3} \mathrm{~A}^{\prime \prime}$ at $12.4(14.612 .9) \mathrm{eV}$ with the same level of theory, i.e. beyond the present photon energy range, and hence it does not contribute to the second band. It is worth noting that we had also tried to calculate the AIE of the $b^{1} A^{\prime}$ state, but theour theoretical calculations aimed at optimizing the-its equilibrium structure of the $b^{1} A^{\prime}$ state did not converge. This may indicate that the $b^{1} A^{\prime}$ electronic state is not stable, agreeing well with our experimental results, since the $\mathrm{CH}_{3} \mathrm{O}_{2}{ }^{+}$cations prepared in the $\mathrm{b}^{1} \mathrm{~A}^{\prime}$ state fully dissociate into the $\mathrm{CH}_{3}{ }^{+}$and $\mathrm{O}_{2}$ fragments, as shown in Fig. 5(a). 
Interestingly, unlike the literature TPES, ${ }^{9}$ in the present SPES there is almost no population in the Franck-Condon gap ( $11.1 \mathrm{eV})$ between the two bands (see Fig. S1). This discrepancy could be explained by the temperature difference involved in the two experiments. The temperature difference could come from the fact that in our case we separate the weak expansion from the thermal gas using the ion ROI, as shown in Fig. 2, and only take into account the cold part of the molecular beam in the SPES. In addition, the different methods to produce the $\mathrm{CH}_{3}$ radical could also contribute somewhat to the temperature difference. We used the reaction $\mathrm{F}+\mathrm{CH}_{4} \longrightarrow \mathrm{CH}_{3}+\mathrm{HF}$ to generate the $\mathrm{CH}_{3}$ radical, since-whereas the literature TPES was obtained using photolysis to initiate the reaction.generate the precursor methyl radical, followed by low pressure expansion inte vacuum which, in the absence of supersonic cooling, yielded a thermalized sample. Therefore, the internal temperature was nearly two times higher than with the present hydrogen-abstraction method. Another explanation for this discrepancy could be the different sensitivity to autoionization resonances of both methods, which are known to affect threshold spectroscopy in general, and leads to significant transition intensities even in wide Franck-Condon gaps. This latter feature of threshold photoionization (SPES and TPES) is routinely utilized in recording breakdown curves even in photon energy regions with no appreciable peaks in the photoelectron spectrum, or to expand the spectroscopic window into the Franck-Condon gap ${ }^{27,28}$.

\section{Breakdown Diagram and the Adiabatic Appearance Energy}

The $\mathrm{X}^{3} \mathrm{~A}^{\prime \prime}$ ground electronic state and the $\mathrm{a}^{1} \mathrm{~A}^{\prime}$ first excited electronic state are bound, as demonstrated in the ms-SPES of the $\mathrm{m} / \mathrm{z}=47$ ions in Fig. 5(a). Earlier theoretical calculations showed that these two states adiabatically correlate to the $\mathrm{CH}_{3}{ }^{+}\left(\mathrm{X}^{1} \mathrm{~A}_{1}\right)+\mathrm{O}_{2}\left(\mathrm{X}^{3} \Sigma_{\mathrm{g}}{ }^{-}\right)$and the $\mathrm{CH}_{3}\left(\mathrm{X}^{2} \mathrm{~A}_{2}\right)+\mathrm{O}_{2}^{+}\left(\mathrm{X}^{2} \Delta_{\mathrm{g}}\right)$ dissociation limits, respectively. ${ }^{6}$

The fractional ion abundances obtained from the ms-SPES of $\mathrm{m} / \mathrm{z}=47$ and 15 plotted as a function of the photon energy yield the breakdown diagram, which are shown in Fig. 6. As the photon energy increases, the energy distribution of the parent cation is shifted to higher energies, thereby leading to more dissociation. Finally, when the photon energy equals the appearance energy of the fragment ion, $\mathrm{AE}_{0 \mathrm{~K}}$ of $\mathrm{CH}_{3}{ }^{+}$here, the whole energy 
distribution is above the dissociation limit, and the ratio of the parent $\mathrm{CH}_{3} \mathrm{O}_{2}{ }^{+}$cation goes to zero. ${ }^{33}$

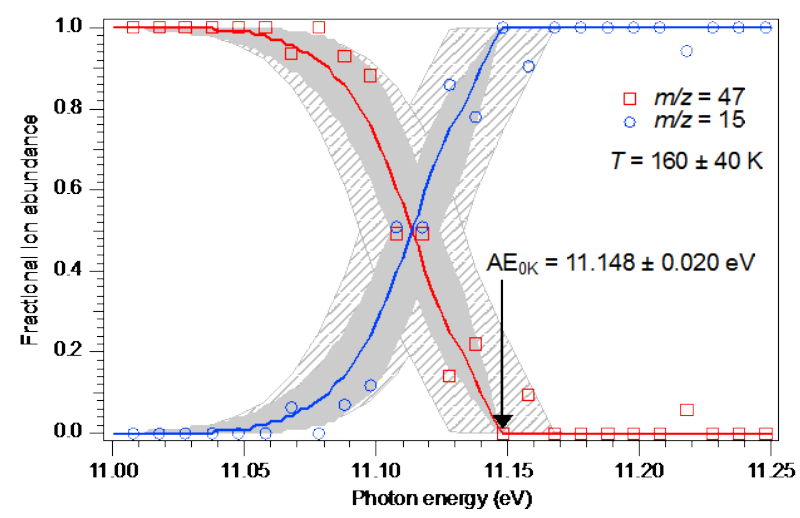

FIG. 6. Breakdown diagram for $\mathrm{CH}_{3} \mathrm{O}_{2}{ }^{+}$. Open symbols are experimentally measured ion abundances and lines are the statistical rate theory modeling of the data. The solid gray area represents the uncertainty in the ion temperature $(160 \pm 40 \mathrm{~K})$, and the patterned area represents the uncertainty in the appearance energy of $\mathrm{CH}_{3}{ }^{+}$fragment ions (11.148 \pm $0.020 \mathrm{eV})$.

The $\mathrm{CH}_{3} \mathrm{O}_{2}{ }^{+}$breakdown diagram is modeled as described by Voronova et al., ${ }^{9}$ including a $\mathrm{CH}_{3}-\mathrm{OO}$ hindered rotor in the energy distribution model for neutral $\mathrm{CH}_{3} \mathrm{O}_{2}$. In short, the $0 \mathrm{~K}$ appearance energy of $\mathrm{CH}_{3}{ }^{+}$and the internal temperature of $\mathrm{CH}_{3} \mathrm{O}_{2}$ were treated as fitting parameters. Since the dissociation is fast on the timescale of the experiment, the breakdown curves depend only on these two variables. Hence, the diagram can be used effectively as a molecular thermometer, similarly to the earlier work by Voronova et al. ${ }^{9}$ As these new experiments were optimized for a higher-quality photoelectron spectrum, the noise in the breakdown curve is more significant and the best fit model temperature and the $0 \mathrm{~K}$ appearance energy of $\mathrm{CH}_{3}{ }^{+}$is determined to be $160 \pm$ $40 \mathrm{~K}$ and $11.1548 \pm 0.02 \theta \mathrm{eV}$, respectively. The $\mathrm{AE}_{0 \mathrm{~K}}$ agrees with the $11.16 \pm 0.05 \mathrm{eV}$ determination of Meloni et al. ${ }^{6}$ and the $11.164 \pm 0.010 \mathrm{eV}$ by Voronova et al. ${ }^{9}$ Then, based on the thermochemical cycle, the bond dissociation energies of the parent cation $\mathrm{CH}_{3} \mathrm{O}_{2}{ }^{+}$and the neutral radical $\mathrm{CH}_{3} \mathrm{O}_{2}$ are determined at $\mathrm{D}_{0}\left(\mathrm{CH}_{3}{ }^{+}-\mathrm{OO}\right)=0.93 \pm 0.02 \mathrm{eV}$ and $\mathrm{D}_{0}\left(\mathrm{CH}_{3}-\mathrm{OO}\right)=1.31 \pm 0.02 \mathrm{eV}$, respectively, with the AIE of $\mathrm{CH}_{3} \mathrm{O}_{2}$ and the literature AIE of the methyl radical.

\section{CONCLUSIONS}


The photoionization of $\mathrm{CH}_{3} \mathrm{O}_{2}$ and unimolecular dissociation of internal energy selected $\mathrm{CH}_{3} \mathrm{O}_{2}{ }^{+}$cations were investigated in the 9.7-12.0 eV photon energy range by the state-of-the-art method of double imaging photoelectron photoion coincidence (i ${ }^{2}$ PEPICO) at the DESIRS beamline of SOLEIL. The $\mathrm{CH}_{3} \mathrm{O}_{2}$ radicals were produced in a microwave discharge flow tube via the reaction of methyl radicals with oxygen molecules, where the methyl radicals were formed via the hydrogen-abstraction of methane. After identifying and separating the different sources of $\mathrm{CH}_{3}{ }^{+}$from photoionization of $\mathrm{CH}_{3}$ or dissociative photoionization of $\mathrm{CH}_{3} \mathrm{O}_{2}$, the full SPES of $\mathrm{CH}_{3} \mathrm{O}_{2}$ was obtained with a resolution of $\sim 10 \mathrm{meV}$ and exhibits two broad bands superimposed with an intricate vibrational structure. The first band of the SPES is attributed to the $\mathrm{X}^{3} \mathrm{~A}^{\prime \prime}$ and $\mathrm{a}^{1} \mathrm{~A}^{\prime}$ overlapped electronic states while the second band is assigned as the $b^{1} \mathrm{~A}^{\prime}$ excited electronic states with the aid of theoretical calculations. The adiabatic ionization energy of $\mathrm{CH}_{3} \mathrm{O}_{2}$ is determined to be $\mathrm{AIE}=10.215 \pm 0.015 \mathrm{eV}$. The vertical ionization energy of the $\mathrm{b}^{1} \mathrm{~A}^{\prime}$ electronic state is determined for the first time-and lies at around $11.5 \mathrm{eV}$.

$\mathrm{CH}_{3} \mathrm{O}_{2}{ }^{+}$cations prepared at the $\mathrm{b}^{1} \mathrm{~A}^{\prime}$ electronic state fully dissociate into $\mathrm{CH}_{3}{ }^{+}$and $\mathrm{O}_{2}$ fragments. The $0 \mathrm{~K}$ appearance energy of the $\mathrm{CH}_{3}{ }^{+}$fragment ion was determined to be $11.1548 \pm 0.02 \theta \mathrm{eV}$ by fitting the breakdown diagram with a $\mathrm{CH}_{3} \mathrm{O}_{2}$ internal temperature of $160 \pm 40 \mathrm{~K}$, which is significantly lower than the one obtained when $\mathrm{CH}_{3}$ is produced by the hydrogen-abstraction of $\mathrm{CH}_{4}$ with photolytically generated $\mathrm{Cl}$. As demonstrated in this work, the ${ }^{2}$ PEPICO combined with the continuous microwave discharge flow tube has proven to be a valuable tool for providing high-accuracy thermochemical data together with rich dynamic information regarding the VUV photoionization and dissociative photoionization of radicals. Other peroxy radicals are being investigated on DESIRS and their high-resolution VUV photodynamics will be the subject of a forthcoming manuscript.

\section{SUPPLEMENTARY MATERIAL}

See the supplementary material for the slow photoelectron spectrum-SPES of $\mathrm{CH}_{3} \mathrm{O}_{2}$ obtained at SOLEIL and its threshold photoelectron spectrum-TPES at the Swiss Light Source (SLS) adapted from J. Phys. Chem. Lett. 9, 534-539 (2018). 


\section{ACKNOWLEDGMENTS}

This work was financially supported by the National Natural Science Foundation of China (Nos. 21773249, 91961123, 91544228), the International Partnership Program of Chinese Academy of Sciences (No. 116134KYSB20170048) and the French Agence Nationale de la Recherche (ANR) under grant ANR-12-BS08-0020-02 (project SYNCHROKIN). C.F. is grateful to the Chinese Academy of Sciences President's International Fellowship Initiative (No. 2018VMA0055) and the Xu Guangqi program (No. 43270ZD). B.S. gratefully acknowledge funding by the National Science Foundation (Grant No. CHE-1665464). The authors thank J.-F. Gil, D. Schleier and A. Roeder for their assistances in the synchrotron experiments and the SOLEIL staff for smoothly running the facility and providing beamtime under proposal 20150802.

\section{REFERENCES}

${ }^{1}$ G. S. Tyndall, R. A. Cox, C. Granier, R. Lesclaux, G. K. Moortgat, M. J. Pilling, A. R. Ravishankara and T. J. Wallington, "Atmospheric chemistry of small organic peroxy radicals," J. Geophys. Res.-Atmos. 106, 12157 (2001).

${ }^{2}$ J. J. Orlando and G. S. Tyndall, "Laboratory studies of organic peroxy radical chemistry: an overview with emphasis on recent issues of atmospheric significance," Chem. Soc. Rev. 41, 6294 (2012).

${ }^{3}$ D.-R. Huang, L.-K. Chu and Y.-P. Lee, "Infrared absorption of gaseous $\mathrm{CH}_{3} \mathrm{OO}$ detected with a step-scan Fourier-transform spectrometer," J. Chem. Phys. 127, 234318 (2007).

${ }^{4}$ E. Assaf, L. Sheps, L. Whalley, D. Heard, A. Tomas, C. Schoemaecker and C. Fittschen, "The Reaction between $\mathrm{CH}_{3} \mathrm{O}_{2}$ and $\mathrm{OH}$ radicals: Product yields and atmospheric implications," Environ. Sci. Technol. 51, 2170 (2017).

${ }^{5}$ T. Berndt, W. Scholz, B. Mentler, L. Fischer, H. Herrmann, M. Kulmala and A. Hansel, "Accretion product formation from self- and cross-reactions of $\mathrm{RO}_{2}$ radicals in the atmosphere," Angew. Chem. Int. Ed. 57, 3820 (2018).

${ }^{6}$ G. Meloni, P. Zou, S. J. Klippenstein, M. Ahmed, S. R. Leone, C. A. Taatjes and D. L. Osborn, "Energy-resolved photoionization of alkylperoxy radicals and the stability of their cations," J. Am. Chem. Soc. 128, 13559 (2006).

${ }^{7}$ Z. Wen, X. Tang, C. Wang, C. Fittschen, T. Wang, C. Zhang, J. Yang, Y. Pan, F. Liu and W. Zhang, "A vacuum ultraviolet photoionization time-of-flight mass spectrometer with high sensitivity for study of gas-phase radical reaction in a flow tube," Int. J. Chem. Kinet. 51, 178 (2019).

${ }^{8}$ A. V. Copan, H. F. Schaefer, III and J. Agarwal, "Examining the ground and first excited states of methyl peroxy radical with high-level coupled-cluster theory," Mol. Phys. 113, 2992 (2015). 
${ }^{9}$ K. Voronova, K. M. Ervin, K. G. Torma, P. Hemberger, A. Bodi, T. Gerber, D. L. Osborn and B. Sztaray, "Radical thermometers, thermochemistry, and photoelectron spectra: a PEPICO study of the methyl peroxy radical," J. Phys. Chem. Lett. 9, 534 (2018).

${ }^{10}$ I. C. Plumb, K. R. Ryan, J. R. Steven and M. F. R. Mulcahy, "Rate coefficient for the reaction of $\mathrm{CH}_{3} \mathrm{O}_{2}$ with $\mathrm{NO}$ at $295 \mathrm{~K}$," J. Phys. Chem. 85, 3136 (1981).

${ }^{11}$ I. R. Slagle and D. Gutman, "Kinetics of polyatomic free radicals produced by laser photolysis. 5. Study of the equlibrium $\mathrm{CH}_{3}+\mathrm{O}_{2}-->\mathrm{CH}_{3} \mathrm{O}_{2}$ between 421 and $538{ }^{0} \mathrm{C}$," J. Am. Chem. Soc. 107, 5342 (1985).

${ }^{12}$ G. Meloni, T. M. Selby, F. Goulay, S. R. Leone, D. L. Osborn and C. A. Taatjes, "Photoionization of 1-alkenylperoxy and alkylperoxy radicals and a general rule for the stability of their cations," J. Am. Chem. Soc. 129, 14019 (2007).

${ }^{13}$ H. B. Fu, Y. J. Hu and E. R. Bernstein, "Generation and detection of alkyl peroxy radicals in a supersonic jet expansion," J. Chem. Phys. 125, 014310 (2006).

${ }^{14}$ X. Tang, X. Zhou, M. Niu, S. Liu, J. Sun, X. Shan, F. Liu and L. Sheng, "A threshold photoelectron-photoion coincidence spectrometer with double velocity imaging using synchrotron radiation," Rev. Sci. Instrum. 80, 113101 (2009).

${ }^{15}$ A. Bodi, P. Hemberger, T. Gerber and B. Sztaray, "A new double imaging velocity focusing coincidence experiment: $i^{2}$ PEPICO," Rev. Sci. Instrum. 83, 083105 (2012). ${ }^{16}$ G. A. Garcia, B. K. C. de Miranda, M. Tia, S. Daly and L. Nahon, "DELICIOUS III: A multipurpose double imaging particle coincidence spectrometer for gas phase vacuum ultraviolet photodynamics studies," Rev. Sci. Instrum. 84, 053112 (2013).

${ }^{17}$ X. Tang, G. A. Garcia and L. Nahon, "Adiabatic ionization energies of the overlapped $\mathrm{A}^{2} \mathrm{~A}_{1}$ and $\mathrm{B}^{2} \mathrm{E}$ electronic states in $\mathrm{CH}_{3} \mathrm{Cl}^{+} / \mathrm{CH}_{3} \mathrm{~F}^{+}$measured with double imaging electron/ion coincidence," Phys. Chem. Chem. Phys. 17, 16858 (2015).

${ }^{18}$ D. V. Chicharro, S. Marggi Poullain, L. Banares, H. R. Hrodmarsson, G. A. Garcia and J.-C. Loison, "Threshold photoelectron spectrum of the $\mathrm{CH}_{2} \mathrm{OO}$ Criegee intermediate," Phys. Chem. Chem. Phys. 21, 12763 (2019).

${ }^{19}$ X. Tang, G. A. Garcia, J. F. Gil and L. Nahon, "Vacuum upgrade and enhanced performances of the double imaging electron/ion coincidence end-station at the vacuum ultraviolet beamline DESIRS," Rev. Sci. Instrum. 86, 123108 (2015).

${ }^{20}$ L. Nahon, N. de Oliveira, G. A. Garcia, J. F. Gil, B. Pilette, O. Marcouille, B. Lagarde and F. Polack, "DESIRS: a state-of-the-art VUV beamline featuring high resolution and variable polarization for spectroscopy and dichroism at SOLEIL," J. Synchrotron Rad. 19, 508 (2012).

${ }^{21}$ G. A. Garcia, X. Tang, J.-F. Gil, L. Nahon, M. Ward, S. Batut, C. Fittschen, C. A. Taatjes, D. L. Osborn and J.-C. Loison, "Synchrotron-based double imaging photoelectron/photoion coincidence spectroscopy of radicals produced in a flow tube: $\mathrm{OH}$ and OD," J. Chem. Phys. 142, 164201 (2015).

${ }^{22}$ NIST Atomic Spectra Database, https://www.nist.gov/pml/atomic-spectra-database, (Retrieved on December 15, 2019)

${ }^{23}$ A. Eppink and D. H. Parker, "Velocity map imaging of ions and electrons using electrostatic lenses: Application in photoelectron and photofragment ion imaging of molecular oxygen," Rev. Sci. Instrum. 68, 3477 (1997).

${ }^{24}$ G. A. Garcia, L. Nahon and I. Powis, "Two-dimensional charged particle image inversion using a polar basis function expansion," Rev. Sci. Instrum. 75, 4989 (2004). 
${ }^{25}$ J. C. Poully, J. P. Schermann, N. Nieuwjaer, F. Lecomte, G. Gregoire, C. Desfrancois, G. A. Garcia, L. Nahon, D. Nandi, L. Poisson and M. Hochlaf, "Photoionization of 2pyridone and 2-hydroxypyridine," Phys. Chem. Chem. Phys. 12, 3566 (2010).

${ }^{26}$ B. Sztáray, K. Voronova, K. G. Torma, K. J. Covert, A. Bodi, P. Hemberger, T. Gerber and D. L. Osborn, "CRF-PEPICO: Double velocity map imaging photoelectron photoion coincidence spectroscopy for reaction kinetics studies," J. Chem. Phys. 147, 013944 (2017).

${ }^{27}$ X. Tang, G. A. Garcia and L. Nahon, "Double imaging photoelectron photoion coincidence sheds new light on the dissociation of state-selected $\mathrm{CH}_{3} \mathrm{~F}^{+}$ions," J. Phys. Chem. A 121, 5763 (2017).

${ }^{28}$ M. Briant, L. Poisson, M. Hochlaf, P. de Pujo, M.-A. Gaveau and B. Soep, "Ar 2 photoelectron spectroscopy mediated by autoionizing states," Phys. Rev. Lett. 109, 193401 (2012).

${ }^{29}$ X. Tang, G. A. Garcia and L. Nahon, " $\mathrm{CH}_{3}{ }^{+}$formation in the dissociation of energyselected $\mathrm{CH}_{3} \mathrm{~F}^{+}$studied by double imaging electron/ion coincidences," J. Phys. Chem. A 119, 5942 (2015).

${ }^{30}$ B. K. C. de Miranda, C. Alcaraz, M. Elhanine, B. Noller, P. Hemberger, I. Fischer, G. A. Garcia, H. Soldi-Lose, B. Gans, L. A. V. Mendes, S. Boye-Peronne, S. Douin, J. Zabka and P. Botschwina, "Threshold photoelectron spectroscopy of the methyl radical isotopomers, $\mathrm{CH}_{3}, \mathrm{CH}_{2} \mathrm{D}, \mathrm{CHD}_{2}$ and $\mathrm{CD}_{3}$ : Synergy between VUV synchrotron radiation experiments and explicitly correlated coupled cluster calculations," J. Phys. Chem. A 114, 4818 (2010).

${ }^{31}$ Y. Zhu, X. Wu, X. Tang, Z. Wen, F. Liu, X. Zhou and W. Zhang, "Synchrotron threshold photoelectron photoion coincidence spectroscopy of radicals produced in a pyrolysis source: The methyl radical," Chem. Phys. Lett. 664, 237 (2016).

${ }^{32}$ M. J. Frisch, G. W. Trucks, H. B. Schlegel, G. E. Scuseria, M. A. Robb, J. R. Cheeseman, G. Scalmani, V. Barone, B. Mennucci and G. A. Petersson, "Gaussian 09, Revision C. 01. Gaussian, Wallingford."

${ }^{33}$ B. Sztaray, A. Bodi and T. Baer, "Modeling unimolecular reactions in photoelectron photoion coincidence experiments," J. Mass Spectrom. 45, 1233 (2010). 